\title{
S血
}

\section{Studies in Second Language Learning and Teaching}

Department of English Studies, Faculty of Pedagogy and Fine Arts, Adam M ickiewicz University, Kalisz

\section{The impact of studying abroad on students' intercultural competence: An interview study}

\author{
Paweł Sobkowiak \\ Adam M ickiewicz University, Poznań, Poland \\ https://orcid.org/0000-0003-4717-3956 \\ pawelsob@amu.edu.pl
}

\begin{abstract}
This paper presents qualitative research examining to what extent sojourns abroad engage their participants in intercultural interactions and whether or not such experience translates into students' intercultural growth. The results of the study demonstrated that studying abroad did not provide students with ample opportunities to immerse into the local community and fully discover a new cultural environment. However, students surrounded by local and their fellow international students met foreign cultures, which motivated them to explore and interpret the encountered diversity, and thus equipped them with knowledge about foreign cultures, sensitizing them to cultural diversity. Sometimes such contacts challenged students' preconceived judgments and stereotypes of specific cultural groups, their ways of thinking, valuing and acting, and resulted, to a lesser or greater extent, in rethinking these, leading to changing attitudes and values. International experiences also stimulated students to self-analyze their own cultural identity, and thereby contributed to their growth in self-awareness in this respect. By offering opportunities for experiencing cultural differences and prompting students to develop coping strategies and to make references to the home culture, the sojourn is thus of significant importance for tertiary students, allowing for fostering their intercultural development to a certain degree.
\end{abstract}

Keywords: contact hypothesis; intercultural encounters; intercultural sensitivity; intercultural competence; study abroad 


\section{Introduction}

Short-term study abroad programs have become increasingly popular among European students, Polish ones included, creating cross-cultural learning opportunities for their participants. Due to the Erasmus+program sponsored by the European Union, students can spend a semester or two at a foreign university hoping not only to expand their professional knowledge but also to develop foreign language proficiency and to learn about the host country, its culture and people. In addition, surrounded by other Erasmus students, it seems they will have ample opportunities to get involved in intercultural collaborations in class and interact with their international peers outside the classroom, talk across a range of diverse cultures and negotiate their particular identities. Student mobility seems to be an excellent opportunity for students to fully immerse in foreign cultures on a daily basis, negotiate meanings and make their ways in this new reality, or even to reinvent themselves (Simpson, 2008; Liddicoat \& Scarino, 2013). Intercultural experience from study abroad should help students raise their capabilities for observation, tolerance for ambiguity and uncertainty, and successful adaptation to new cultural settings, that is, for unfamiliar settings attributable to cultural context, equipping them for grasping, reasoning and behaving appropriately and effectively in situations characterized by cultural diversity (Ang et al., 2007; Earley $\&$ Ang, 2003). Of course, these outcomes will not happen automatically and will depend on a range of factors, mainly on whether students themselves recognize and appreciate such opportunities for direct, meaningful participation and engagement.

This article will present empirical research investigating whether and to what extent study abroad experience fosters students' intercultural development, that is, whether and to what extent it helps them acquire "the ability to interact effectively with people of cultures other than one's own" (Byram, 2000, p. 297). In other words, the author will try to examine whether sojourns abroad affect students' intercultural knowledge, their awareness of different values and behaviors of people from other cultures and social groups, as well as their attitudes toward otherness, and a willingness to accept differences and approach foreigners in a non-judgmental way. Taking into consideration the current speed of globalization in almost every sphere of life and the increased internationalization of tertiary level education, cross-cultural contact appears to be inevitable for young people (Cushner $\&$ Brislin, 1996). Consequently, students' growth in intercultural competence is prerequisite for preparing them for diverse cultural settings, that is, to study with international students at their home universities, to attend lectures and seminars run by professors from different cultures, to communicate with foreigners while traveling, and in the long-run, to work with a culturally diverse workforce in a range of international 
workplaces. Since empirical research carried out in the European context does not unanimously confirm a positive impact of the sojourn on an individual's intercultural growth, the current study seeks to provide more data on the Erasmus experience and thus seems timely.

\section{Literature review}

There has been extensive research into students' mobility experiences with various outcomes, such as increased language proficiency, reduction of ethnocentrism, awareness of other cultures and one's own, and growth in intercultural communication skills and professional competence (Cushner \& Karim, 2003; Halse, 1996; Hill \& Thomas, 2002; M cCabe, 2001; Wilson, 1983). However, conflicting results have been obtained from such studies concerning the impact of study abroad on students' intercultural competence. Whereas some researchers are convinced that optimal intercultural learning stems from direct contacts (Czura, 2017; Halualani, 2008; Kormos \& Csizér, 2007; Mak, Brown, \& Wadey, 2014; M cAllister, Whiteford, Hill, Thomas, \& Fitzgerald, 2006), others claim that the results of student mobility are highly variable and students may return home more ethnocentric and less willing to interact with people who come from different linguistic and cultural environments (Jackson, 2015; Vande Berg, 2007).

It is notew orthy that there is empirical research supporting the claim that an increase in intercultural sensitivity can be achieved through education and training, without the need for staying abroad (Altschuler, Sussman, \& Kachur, 2003; Bennett, Bennett, \& Allen, 1999; Paige, 1993). Kelly (1963) maintains that an individual can witness an event without ever experiencing it. It has been evidenced that intercultural contact per se does not directly change attitudes, but what contributes to such a change is the mediation of the perceived importance of the contact experience (Van Dick, Wagner, Pettigrew, Christ, \& Wolf, 2004).

However, a plethora of studies have attempted to support the positive impact of study abroad programs. Paige, Cohen, and Shively (2004) found that sojourns did show significant improvement in the participants' intercultural sensitivity. In a similar vein, students investigated by Engle and Engle (2004) demonstrated growth in intercultural sensitivity following one semester- or two semester-long studying abroad. In addition, the latter group's gains outnumbered intercultural sensitivity of the former. Czerwionka, Artamonowa, and Barbosa (2015) demonstrated that student sojourners exhibited an increase in knowledge related to most intercultural knowledge types, and the greatest growth was noticed in knowledge themes of Big C (culture and history), daily life, food and drink, and values and politics. Since Lussier (2007) claimed that intercultural knowledge is a basic component requisite for intercultural skills and attitudes, the researchers 
concluded that study abroad positively impacts the development of intercultural competence. Fang and Baker (2017) reported that short-term study abroad contributed to students' change in both attitudes and behaviors, leading to their better understanding of other people and cultures, more openness to diversity, broadening the horizons and the development of a more inclusive mind toward the world. Likewise, Mitchell (2012) provided compelling evidence that student mobility results in attitudinal changes about Europe and increases levels of support for the EU, as well as the extent of identifying as European.

The study carried out by the author and discussed in the subsequent parts of this paper assumes that intercultural communicative competence (ICC), "the ability to communicate effectively and appropriately in intercultural situations based on one's intercultural knowledge, skills, and attitudes" (Deardorff, 2006, pp. 247-248) is developmental in nature (i.e., it is a lifelong process with no final stage). ICC shifts over time, increases with experiences in intercultural contacts and is context driven - contextual variables influence its development. Another theoretical foundation underlying the study is Bennett's (1993) developmental model of intercultural sensitivity (DMIS) describing individuals' reactions to intercultural differences on a continuum ranging from ethnocentric to ethnorelative stages. As for a context-based perspective on ICC, Ting-Toomey's (1999) model has been adopted. The researcher assumes that the process of ICC development does not occur in a vacuum but only through interactions with and in relation to persons from diverse backgrounds. Thus, what is requisite for its growth is reflection and mindfulness - through critical analysis of experience individuals become aware of how they are intentionally developing specific aspects of ICC.

Another theoretical framework the paper applies is contact theory, or the contact hypothesis (Allport, 1954), which provides a means of understanding and designing programs aimed at improving intergroup relations (Hean $\&$ Dickinson, 2005; Pettigrew \& Tropp, 2005; Pettigrew, Tropp, Wagner, \& Christ, 2011). According to the intergroup contact hypothesis, bringing people from diverse linguistic and cultural backgrounds together does not naturally result in a sense of cultural tolerance and acceptance of others, nor does it make them engaged with "out-group" members, open-minded and non-prejudiced toward them. For direct interactions with foreigners to translate into enhanced ICC, certain conditions have to be met, such as common goals, equal group status within the situation, intergroup cooperation, and authority or community support. A range of studies proved that the favorable circumstances outlined by Allport, that is, meaningful international and intergroup contact, might have positive effects on intercultural attitudes and reduce intergroup bias, causing individuals to recategorize themselves as a single group ("we") rather than as two separate groups ("us" and "them"; Desforges et al., 1997; Gaertner, Dovidio, Anastasio, Bachman, 
\& Rust, 1993; Hamberger \& Hewstone, 1997; Stangor, Jonas, Stroebe, \& Hewstone, 1996). Recent research in community psychology has suggested a potential use of the contact theory as a tool for building intercultural relationships (Townley, Kloos, Green, \& Franco, 2011).

The contact hypothesis helped conceptualize Erasmus+ study abroad program as linked with attitudinal and identity change because several of the contact hypothesis conditions are congruent with Erasmus organizational values. Equal status is provided by recommending participatory learning at host universities, that is, through pair- and group work and engaging students in a range of projects. In addition, equal status is strengthened by the fact that Erasmus participants are similar in age, life status and immediate activities they get involved in. The students have common goals, that is, they want to graduate with good marks and/ or find a romantic partner and build a range of other meaningful relationships during the sojourn, thus seeking mutual understanding of human diversity is crucial for them. As for intergroup cooperation, it may be offered by the types of activities in which the students engage. For example, they could spend time together preparing meals together or doing sports. Support of local authority is ensured through giving the participants permission to enter into the community of students at a given university.

\section{The study}

\subsection{Rationale, setting and aim}

The impetus for the study came from the author's interest in intercultural foreign language (FL) education. Poland, where the author is based, is a homogeneous country where students go through a largely mono-cultural socialization. They are taught English by Polish graduates of FL departments and, consequently, at school have very limited intercultural input. Classroom instruction offers them very few channels to experience and understand intercultural communication. Likewise, the level of internationalization of Polish universities is very low. Although Polish students travel for holidays abroad, use the Internet and other media, and know people who take part in economic migration, it is difficult to determine the quality of such contacts, to what extent students experience the difference between their own perception of reality and that of people who are culturally different, and whether students reflect on their contacts with representatives of diverse cultures. This makes it requisite to investigate and evaluate alternatives for moving students to higher levels of intercultural sensitivity.

The research project was meant to investigate students' perception of the development of intercultural competence, that is, knowledge, skills and attitudes through exploring their experiences during staying abroad. The author wanted to 
assess whether and to what extent the students "transformed" in an international environment and became more open-minded and intercultural, that is, whether the sojourn abroad translated into their intercultural development. In the study, intercultural contact was perceived as personal, direct contact with native and non-native speakers of English as a lingua franca, that is, "any use of English among speakers of different first languages for whom English is the communicative medium of choice, and often the only option" (Seidlhofer, 2011, p. 7). Contact with cultural products, mainly different types of media, for example, TV, Internet, books, movies and magazines, despite their high capacity as possible mediators of intercultural information, and also being available within Poland, was outside the scope of the research.

The study, exploratory in nature, was guided by the following three specific research questions:

1. To what extent did students engage in meaningful intercultural interactions?

2. To what extent did they reflect on their cross-cultural experiences and how did they interpret their interactions?

3. How did intercultural contacts, in students' view, change them and their attitudes or preconceived notions about their culturally different peers?

\subsection{Method}

Given the complex nature of both the phenomenon being studied and the research questions, a qualitative approach was adopted, which allowed for a more direct method of gauging the researched problem.

\subsection{Participants}

The participants were Polish students who participated in the Erasmus+ program the year preceding the study. An interview sample was chosen from the Erasmus databases at one large and one middle-sized, flagship, public universities located in a large city with half a million inhabitants, in Central-Western Poland. The student body at both universities is very homogeneous, including a very low number of international students (2.05\% and 3.69\% respectively). All students listed in both databases were e-mailed and invited to participate in the study. The response rate, though, was very small - only 13 of the students agreed to be interviewed. One student was excluded from the sample since he came from a bilingual family and the study focused on students raised and socialized in mono-cultural and mono-lingual settings. Thus, the logic of purposive sampling to increase validity of the study was followed (Corbin \& Strauss, 2007; Silverman, 2013). Ethics approval based upon informed consent procedures was followed. 
The sample of 12 interview participants varied across the attributes of gender, class year (age) and level of studies. The demographics of the accessed participants included a close to equal gender split with 7 females and 5 males. There was also a diversified representation of age among the participants: from 20 to 25 . Almost half of the sample were graduate students (5), while the remaining participants were undergraduates (7). Their majors ranged from law, through administration to management. All the participants spoke English at a fairly advanced level of proficiency, high enough to be able to participate in courses, lectures and seminars in English while they studied abroad. The majority knew another foreign language or even two others from school, private lessons and self-study. They studied in as many as $10 \mathrm{EU}$ countries: Belgium, Croatia, Great Britain, Finland, France, Italy, the Netherlands (2), Portugal, Slovenia and Spain (2) in the span of either one (9 students) or two semesters (3 students). The majority of the participants were unfamiliar with the interviewer ( 3 interviewees were his current or former students).

To make sure that the participants had no prior experience of extensive intercultural contacts, they were asked whether they had ever lived abroad for a longer period of time or had a relationship in Poland with a foreign partner. No such experience was reported (one student worked in Norway four consecutive summers but was surrounded by fellow Polish workers). In addition, no interviewee participated in intercultural training prior to the sojourn.

\subsection{Data collection and procedures}

The author carried out semi-structured interviews with the participants of the study. The researcher not only asked a set of prepared questions but also followed the participants' lead. To avoid response bias (students offering acceptable responses) and over-directiveness, the students were prompted to add their comments freely during the interviews and make digressions. The interview questions were piloted with one student from the target population to check for clarity, which resulted in a few changes in their wording to resolve the ambiguities. The interviews were conducted in Polish, in the spring of 2017, by the author himself, recorded and transcribed verbatim. In order to keep the identity of the participants anonymous their names were replaced by symbols (from S1 to S12). Recording allowed an in-depth analysis of the manner in which the students' stories were told and the tone of the comments. The scripts were coded for units of meaning. Such procedures were employed to follow rigor demanded in qualitative research and to achieve more valid findings. The interviews took place individually - three took place in a quiet room at the university venue where the author is employed, while the remaining ones were done via Skype. 
The interviews took from 35 to 60 minutes, amounting to the total of 549 minutes ( $M=45.75 ; S D=8.44 ; C V=18.45 \%$ ).

The interviewing protocol revolved around 15 closed and semi-structured questions related to four topics, which were supposed to guide both the interviewer and the students (see Appendix). First, the biographical data were collected and the participants were asked about the country where they had studied, the reasons why they had decided to study abroad, and whether their objectives had been achieved. Second, the students were asked about preparation before going abroad, namely whether or not they had tried to learn about the country, its inhabitants and culture where they were supposed to spend one semester or two. The interviewer was also interested in whether or not they had taken part in intercultural training. The interviewees were queried about their prior intercultural experience, whether they had traveled individually before participating in the Erasmus+ program or had lived with or kept in touch on a regular basis with an individual from another culture. This question was designed to eliminate from the sample individuals with close and regular cross-cultural contacts prior to their sojourns.

Another question dealt with the length of time the interviewees spent with people from diverse cultures (both foreigners and locals), which was relevant to determine the potential effect of the sojourn on the students. Seven questions about students' experiences with contacting both locals and foreigners were meant to explore their intercultural awareness and notice to what extent it had changed (i.e., grew). The questions from this group also checked students' intercultural learning and asked whether the students had experienced culture shock - the interviewees were prompted to discuss critical incidents they had experienced during their sojourns. The critical incident approach was utilized in this part of the study since it is considered a valuable research tool, especially with respect to understanding intercultural interactions and stimulating reflective thinking, which leads to reflective judgment, an important aspect of intercultural competence (M cAllister et al., 2006).

The interviewer ended each interview session by asking the students to selfreport in detail on the changes they had observed in themselves following the stay abroad. The researcher also asked the participants what they had learned about themselves and whether and to what extent they perceived themselves in a new way after the sojourn abroad. The final question concerned the changes which the respondents noticed in themselves and what, in their views, contributed to them.

\subsection{Data analysis}

Coding allowed the researcher to identify the key categories and data were analyzed in several steps, following the principles of the constant comparative 
analysis (Rice \& Ezzy, 1999). These categories were then grouped into the following themes:
1) aspirations and expectations of the intercultural experience;
2) cultural knowledge and attitudes related to the lifestyles of various com- munities represented by the host country community and fellow Erasmus students (housing, health, eating, drinking, clothing, festivities, safety);
3) similarities and differences between Poland and the host country;
4) realizing and overcoming stereotypes associated with different nationalities;
5) experiencing cultural shock (critical incidents);
6) intercultural contact and personal coping strategies.

\section{Results and discussion}

The analysis of the interview data is presented according to the three research questions and the themes identified at the data analysis stage discussed earlier.

\subsection{Expectations}

A significant number of the participants declared that being exposed to a new culture, along with the desire to improve foreign language/s proficiency, had been the main reasons for them to study abroad ( 7 and 5 interviewees respectively). The former aim seems pertinent because the students wanted to fit into the new environment and communicate adequately and effectively (this outcome confirms the study by Elola \& Oskoz, 2008). A number of students explicitly discussed the positive relationship between development of English use and proficiency, and their sojourns. They maintained that study abroad helped them lower their anxiety when speaking English and gain more confidence to use it: "At first I was reluctant to talk to local and other foreign students because of a language barrier, but step by step I managed to overcome it" (S5). ${ }^{1}$ The research participants did not perceive English as a threat to their national identity nor as a tool positioning them negatively, which echoes the outcome of Fang and Baker (2017). Since community building is rooted in communication (Deutsch, 1953), this finding demonstrates that the students were well equipped to get involved in meaningful interactions while abroad. This claim concerning the educational advantages of student mobility (i.e., an opportunity to learn the language and become familiar with its culture) was supported in a range of other studies (e.g., Mitchell, 2012). In a similar vein, English language proficiency and confidence

\footnotetext{
${ }^{1}$ All quotes were translated from Polish into English by the author.
} 
seem to be related to the ability "to develop a sense of identity and intercultural citizenship through English" (Fang \& Baker, 2017, p. 13).

Three of the students emphasized that they had wanted to live in "the Erasmus bubble" (i.e., surrounded by other Erasmus students from a range of different countries). Six respondents wanted to establish new friendships. Those answers showed that the participants felt curious about exploring diverse cultures, which indicates their developed motivational domain of culture intelligence (CQ), a fundamental predisposition for becoming intercultural (Ang $\&$ Van Dyne, 2008). The interviewees' decisions to study abroad partially stemmed from cherished family traditions, that is, the majority acknowledged traveling abroad every summer before the sojourn (only 1 did not). This corroborates previous studies which show that students who are willing to study abroad constitute a particular subset (i.e., one with most cultural and economic capital; Otero \& McCoshan, 2006), self-identified as European and with the most European outlooks and attitudes (M itchell, 2012).

\subsection{Intercultural experience}

The interviewed students did not associate intercultural contact with merely being a student at a university attended by other international students. The collected narratives revealed that they did their best so that their stays abroad would go beyond mere presence in the proximity to local and other Erasmus students. The participants were aware that learning about new cultures required active, direct forms, that is, their personal engagements - getting involved in meaningful communication with individuals who were raised in culturally different backgrounds. Thus, they formed numerous acquaintances that yielded discussion of a range of issues, cultural differences included. In the interview sessions, the students declared they viewed their international Erasmus peers, who constituted their primary social group in the sojourn, as representatives of diverse cultures (i.e., they realized that those new friendships were inseparable from and dependent upon culture). From the very beginning, the students did not treat them as strangers and very quickly integrated them into their everyday contact networks. The respondents perceived interaction with them as intercultural and realized that such encounters could create a range of impediments both sides would have to overcome.

The interviewees demonstrated curiosity about novelty, genuine interest in students from other national groups and openness to their cultures. They sought and seized opportunities to spend most of the time with their study abroad counterparts and local students. In fact, in the interviews they reported socializing in an international, multi-national group, and only two students declared that they had 
socialized primarily with host country students - they had a local boyfriend/girlfriend respectively. Researchers investigating the contact hypothesis in the context of student mobility focused on the sojourners' integrative experience with the host society (Fligstein, 2008; Stangor at al., 1996). This, however, was not reported by the students interviewed in the current study - their immersion in the host culture was limited to contacts with local students, and so they did not fully utilize the opportunity to become direct observers of local people and their cultures. Such firsthand experience (i.e., participating in the host culture itself) could have piqued the participants' curiosity into local culture, prompting them to explore it profoundly and consequently helping them achieve a greater level of awareness of the diversity among and within the host country (Elola \& Oskoz, 2008). The data collected here confirm the findings by M urphy-Lejeune (2002) and Mitchell (2012).

The interviewed sample tried to limit the time spent with Polish students to make good use of being exposed to foreign cultures and otherness; only 1 interviewee shared a room in a dorm with a Polish student ( 6 had a single room, 5 had a roommate from a foreign country, and none shared a room with a student from the host country). All the interviewees had a lot of informal conversations in English. They made friends with local students who attended their classes, tried to spend considerable time with them in the afternoon, attending tourist attractions, hanging out, going to pubs or parties together, and thus they were immersed to a certain extent in the environment characterized by cultural diversity. Their lives were inherently intertwined with intercultural interactions, which allowed for interpreting the situation, analyzing reactions of international students from other cultures and assessing critical incidents, together with their consequences. The following excerpts from the interviews illustrate this:

M ost of the time I hung out and socialized with international students. (S3)

I did not spend time with Polish students at all since I wanted to practice my English. (S5)

I went on several excursions for Erasmus students organized by the program coordinators and visited a few places. (S10)

I spent $99 \%$ of the time with foreign peers, both Erasmus and local students. (S12)

\subsection{Cultural knowledge, diverse lifestyles, similarities and differences with Poland}

As has already been mentioned, the students socialized primarily with their study abroad counterparts and, to a lesser degree, with local students. This lack of daily contact with host communities allowed for gaining only surface cultural knowledge of the countries where they studied. However, the sojourn provided the interviewees with sufficient spaces for critical discoveries about themselves 
and others. The students voiced rather conciliatory and level-headed opinions about life in a particular foreign culture. In addition, positive attitudes toward foreign cultures prevailed in their accounts. For example, in the interviewees' views, the pace of life in Belgium, Croatia, the Netherlands, France, Italy, Portugal, Slovenia and Spain was much slower and more stress-free than that of people in Poland. Keeping work-life balance seemed to be extremely important for local people there. However, they noticed that speed of life may differ within a particular country: "Barcelona is faster than Valencia" (S2).

Several of the countries have a completely different meals schedule, with dinner being the main meal, served in the evening (Belgium, France, Portugal, Italy). In many countries there is a lunch break during the day; however, quite surprisingly, "in northern Italy, which is more Europeanized, there are no siestas" (S3). Whereas healthy food is extremely popular in the Netherlands ("There are a lot of vegans and vegetarians" [S9]), "semi-finished food products are widely purchased and consumed in Finland. Because of historical reasons, national cuisine has not developed there, with potatoes with onions and fish being extremely popular among the Finns" (S11).

Coffee drinking has been ritualized in Italy: "Italians drink different coffee types at various times of the day, in a seated or standing position, depending on the circumstances. Furthermore, wine is widely consumed at dinner, even by children, for whom it is served diluted" (S3). In Belgium, "beer is loved and perceived as national heritage; diverse ranges have to be drunk in a specially designed glasses" (S12). In Croatia, "wine is mixed with carbonated soft drinks" (S5).

Although in the students' narratives the dress code seems to have standardized across the continent and the same brands are available in all countries ("I met in Croatia a girl wearing the same jacket as the one I purchased in Poland" [S5]), they recognized some distinguishing trends and features in this respect. For example, the Dutch and the Croats pay less attention than the Poles to what they wear: "Women in tracksuits and without make-up shopping in a mall are characteristic of the Dutch landscape" (S9). One interview respondent was surprised that "women in Croatia wear tracksuits at very formal occasions along with expensive jewelry" (S5). Other students said that "the Finns get dressed only to be warm and not to stand out" (S11), "the Croats wear thick jackets in relatively high temperatures" (S5) and "the Belgians wear extravagant and eccentric outfits; for example, males wear colorful socks" (S12). The participants noted unique, dressing traditions at some universities. For example, law students in Portugal wear special coats resembling capes ("they were the prototypes for J. K. Rowling's characters in Harry Potter" [S1]) and Finnish students can be distinguished by a special kind of trousers (overalls or dungarees): "Each university has a different type" (S11). 
It might be surprising that such a stereotypical view was so universal in the students' narratives. This might have stemmed from the fact that their access to life of local people was limited to casual meetings in public places, allowing only for surface observations. In addition, the majority studied in large cities with a substantial flow of tourists, which also shaped, blurred and distorted the landscape. The interviews demonstrated that the participants had gained insight mostly into surface issues like dress and food; their observations seem quite simplistic and, as in many other studies, for example, Anderson, Lawton, Rexeisen, and Hubbard (2006) and Czerwionka et al. (2015), show quite an "external" perspective on the part of the participants. The findings of the current study demonstrated that most of the students show propensity to minimize cultural differences, which is characteristic of the minimization phase in Bennett's DM IS (1993). In this stage, individuals share the generalized belief that everyone is fundamentally the same, and differences are acknowledged but minimized and perceived as unimportant, compared to cultural similarities. However, some of the respondents were more mindful and noticed differences and peculiarities concerning the host country in many more domains:

In Holland people leave shoes outside while entering houses. (S9)

Spaniards spend a lot of time in cafes. This refers also to old people. (S10)

Finns value highly their personal zones, which is manifested by keeping a larger physical distance with an interlocutor. They seem to be very calm, self-oriented and never say "Can I help you?" when they see something wrong is going on with you. (S11)

In Belgium people do not say thank you after meals. At first I found it irritating, because for me it is an expression of gratitude to a person who dedicated her/his time to prepare a meal. Oncel asked about this the local people l learned that cooking, in their opinion, is perceived as enjoyment on the part of the person who did the cooking. (S12)

In two accounts the issue of safety was discussed. For example, Finland seemed to be exceptionally safe for one respondent: "I was surprised there was no need to padlock bicycles. On trains passengers left their valuable laptops unattended and went to a dining car. In both cases nothing disappeared" (S11). In a similar vein, one student noted a strong, in her opinion, social trend: "I was surprised that in a liberal Belgium still a patriarchal model of family dominates, i.e., it is a woman who cooks meals, the model is even duplicated among young couples, a great number of young women want to be housewives. In addition, 'to be' over 'to have' approach to life prevails" (S12).

\subsection{National stereotyping}

Although the interviewees reported that student mobility had made them more interested in other European countries, people and cultures, quite broad national 
stereotyping is evident in the respondents' reports. Their narratives revealed, for example, beliefs that people from Belgium, France, Slovenia and Spain are very family-oriented:

The Dutch care about order around their home vicinity and foster the culture of transparency, manifested, among others, by houses with large, free-from-curtains windows. They leave their shoes outside before entering the house. Furthermore, they are crazy about DIY, probably due to bad weather. They are also nicer, much more sincere and more direct in contact than Poles. Generally, the Dutch are more interested in their own lives than in other people's affairs. (S4)

The Portuguese are often late and very loud. (S1)

... and so are the Spaniards, especially women. (S2)

The Slovenes like to be on the go and work out a lot. (S10)

The Spaniards love celebrating together and are very attached to their traditions. They even organize the birthday of the street's patron. (S2)

The Belgians are quite reserved and withdrawn. I had to initiate interactions. (S12)

The participants' accounts evidenced how university education is organized in different countries. For example, "in France, the university infrastructure is well-developed and tons of handouts are distributed in classes/lectures" (S6). The interview data revealed that the majority of the students (11) got involved in pair- or group-work with representatives from a range of countries. Four of them claimed that although they still thought about their international peers in terms of nationalities they represented, they noticed no differences in the way they worked. The remaining seven reported quite a large diversity across cultures. Their reports, however, were full of culture-specific generalizations and stereotyping. When the students reported some problems (e.g., with keeping the deadline for the project), they referred to nationality as if it seemed to be more relevant in the interpretation of the situation than the inappropriateness of the student's behavior against universally accepted values or norms, such as lack of commitment or responsibility. This created the impression as if the country of a particular student's origin contributed to high or bad quality of his/her performance more than their individual approach.

The sample was not homogeneous in the accounts regarding the way their international peers worked in class. A few interviewees used national labels in their reports, explicitly showing disregard or bias toward the presented group, which confirms the findings of previous studies (e.g., Fang \& Baker, 2017). For example, the Italian students were presented as unmindful, scatterbrained and easy-going. Neither did they want to get deeply involved in a project, nor did 
they care for the deadlines. They wanted to do everything by means of social media: "They avoided face-to-face contacts outside the class" (S3). Female students from Slovenia wanted to cheat: "We were supposed to create our own start-up, they wanted to resort to the one already set up by somebody else" (S10). However, in the majority of the reports negative attitudes were well balanced with positive ones, and positive assessment prevailed. For example, one student reported that "a female student from Finland stood out because of her high English proficiency and she approached every single task very seriously" (S6). Another participant noted that "a male student from Hong Kong was always late but very conscientious" (S9). Germans were perceived as very similar to Polish people: "I liked working with Germans most: We distributed subtasks, everybody did his/ her share of the work, they met deadlines" (S11). Some interviewees managed to go beyond national stereotyping in their descriptions, which is well illustrated by the following comment: "The experience of group-work with international students convinced me not to resort to national labels when assessing people - the way a person works depends on his/ her individual characteristics and approach to work, and not on the country he/she originates from" (S10).

In a similar vein, the collected narratives demonstrated marked discrepancy regarding how the study participants approached their international peers. The majority of the respondents claimed that they tried to be culturally conscious in interactions with international peers - they tried to be unprejudiced, rejected tokenizing and showed goodwill and sincerity toward their culturally diverse interlocutors. They tried to listen to people and their experiences; if confronted with something weird or incomprehensible, they resorted to observation, analysis and exploration. If they did not grasp something, they did research themselves or asked their interactants for explanation. However, a few reports revealed that the students viewed culture from a specific, country-related and nation-bound perspective (especially in reference to their Muslim peers). The story of one male respondent showed that the sojourn had strengthened his stereotypical thinking concerning Muslims. He believed his Turkish peer was very patriarchal and demonstrated superiority toward women, who he believed accepted an inferior position: "I was shocked when I noticed he never shook hands with women while doing it with men, nor targeted them directly in a conversation" (S11). A few other respondents admitted that they were preemptive and "tried not to talk about religion so as not to provoke conflict" (S1). Such nation-bound understanding of culture is perceived as a serious impediment to cross-cultural contacts.

A great many stories evidenced in the study depicted contradictory behaviors of representatives of the same nationality confirming that people from the same culture can differ tremendously and the first-hand experience the interviewees had helped them realize this. For example, one student noticed inconsistency 
concerning how some Muslim students approached their religion: "My Turkish fellow student, on the one hand, practiced Ramadan, but, on the other, did not abstain from toxic substances or alcohol, which his religion prohibits" (S4). What struck two other informants about their M uslim peers was their religious commitment. Their female M uslim fellow students prayed five times a day, one had religious symbols on her desktop wallpaper and was eager to talk about her religion, and another had a special application on her mobile, which was to remind her of prayer times. One female Muslim student wore a hijab even in the shower: "It never proved problematic for her; she perceived this as routine" (S9). Thus, it seems safe to conclude that although a lot of national stereotyping was reported in the interviews, contact with international students increased the study participants' awareness of diversity, which should be conducive to their becoming more sensitive to cultural differences in the future.

\subsection{Cultural shock and critical incidents}

The majority of the sample did not experience cultural shock probably because they all studied in European countries, which, as most of the interviewed students highlighted, are quite similar: "In contemporary, globalized Europe there is not much diversity between countries" (S9). Some of the participants were even surprised at this similarity of cultures: "I thought countries differ much more" (S11). Only one female interviewee who had studied in Spain mentioned being shocked at a job interview - she expressed discomfort relative to being kissed on both cheeks by the interviewer who was a complete stranger to her. According to Tang and Choi (2004), negative experiences with individuals from other cultures may turn valuable and promote intercultural development. However, the narratives of other students did not contain evidence of such huge cultural differences - although they noticed and reported quite a few differences between life in the country of their residence and life in Poland, they were never confronted with inappropriate behaviors of people from other cultures which would violate their comfort zones. This corroborates previous studies (Czura, 2017; Zaykovskaya, Rawal, \& De Costa, 2017).

All but one interviewee reported witnessing no critical incidents during their sojourns. However, the narrative of the student who did encounter a situation he considered problematic and confusing because of a cultural clash was quite articulate: "I wanted to shake hands with a M uslim girl from Great Britain I met, but she refused (stepped back), which I found rather surprising. But I apologized quickly. I didn't know female M uslims can't shake hands with men" (S8). Lack of such experience may have resulted from the fact that, as mentioned earlier, the participants spent most of the time abroad on campus, and even 
when they attended social events outside, they were accompanied by other Erasmus or local students. Their contact with other locals was minute.

\subsection{Reflecting on intercultural experiences}

The interviewees appreciated the fact that study abroad provided them with ample opportunities to interact with culturally diverse students and viewed them as "bonuses" or "added value" of student mobility. They were eager to interact with foreigners because in Poland meeting individuals from different cultures is not part of the daily experience. In addition, the participants stated that those direct, meaningful contacts with foreigners had prompted them to think reflectively not only about the situations they had found themselves in, but also about how they themselves thought, viewed and might act toward other cultures on a daily basis. Analyzing various intercultural situations led the respondents to understand that cultural context affects different aspects of their lives. This finding confirms the outcomes of other research on study abroad in this respect, showing it as a positive experience leading ultimately to growth in participants' ICC development (e.g., Anderson et al., 2006; Elola \& Oskoz, 2008; Fang \& Baker, 2017; M itchell, 2012).

According to intercultural contact scholars, recognizing interlocutors as culturally different representatives of a specific cultural group is a precondition for an opportunity to rethink an individual's attitudes toward otherness and reduce their prejudices and biases (Hewstone, 1994). As evidenced from the collected data, the interviewed students utilized their sojourns in this respect by practicing reflective thinking, the capacity leading to reflective judgment, which appears to be critical for intercultural development:

I tried to reflect on my intercultural experience on a daily basis and tried to refer my observations to my future decisions, situations. . . . At first same sex couples holding hands or kissing each other in public shocked me, but step by step I tried to understand why they did this. (S1)

I tried not to assess people. Instead I focused on careful observation, analysis and interpretation. (S2)

I tried to understand their perspective, and asked a lot of questions. (S3)

Study abroad was an impulse to self-analyze. I developed a social instinct. (S4)

The data demonstrated that in face to face contact with peers from other cultures the students were very mindful and paid attention to cultural differences and social nuances, which yielded helpful insights and deeper understanding of cultural differences: "In Portugal dinner is eaten much later than in Poland" (S1), "I witnessed how graduation is celebrated in Italy among friends. Flour and eggs 
are thrown at a graduating student, and finally he/she is forced into water fully dressed" (S3). Simultaneously, direct interactions with students from a range of diverse cultures raised the respondents' awareness of their own cultural identity. Most of the interviewees tried to be ambassadors of their country, which was manifested, among others, by preparing Polish national dishes for international fellow students, explaining Polish customs to them, exhibiting the Polish flag in a room or debunking the unfavorable myths surrounding Poland and Polish people:

I am proud to be Polish, especially of Polish traditions, which, in my opinion, should be cherished. I was among the students who organized the Independence Day for the Erasmus community, I even wore a traditional folk costume. (S2)

When we organized a Polish day I plaited my hair in a typical Slavonic way and prepared a beetroot soup and dumplings. (S7)

Although I admired "perfect order" and planning in the Netherlands, I realized that Polish spontaneity suits me fine. I noticed that Polish grocery products are of much higher quality. I tried to talk a lot about Poland and encouraged my fellow international students to visit my homeland, simultaneously trying to reject the stereotype of Poland as a worse, second-category EU country. (S8)

The participants' engagingly honest comments showed that they did not approach foreign cultures ethnocentrically. Although they sustained some "home preferences," for example, regarding eating and drinking, they did not compare foreign practices unfavorably with those with which they were familiar in Poland, and they did not respond to cultural differences negatively. The students did not tend to perceive their home culture as superior as no patronizing or judgmental comments regarding foreign cultures were reported. They tried to be objective, which occasionally led even to reformulating some opinions and not favorable assessment of their own country and its inhabitants: "Polish people are still very closed, full of prejudices and fears of all kinds, reluctant to start or meet anything new" (S6). The respondents treated other cultures with respect and held a realistic view of their homeland: "I like the Dutch culture of transparency, manifested by leaving the windows open, which allows passers-by a full view of your living quarter and shows that you have nothing to hide" (S4). Neither did they adopt a critical stance toward the countries where they stayed nor their inhabitants. This shows the students' worldview development and their progress on Bennett's DMIS ethnocentric/ethnorelative continuum. However, occasionally a reinforcement of their Polish identity could be observed, especially when their fellow international students showed ignorance and complete lack of basic knowledge concerning Poland: 
It got on my nerves when they asked me if there were water parks in Poland. (S2)

I found it frustrating that the local students didn't know their country's history, such as the fact that in the second world war the Netherlands was liberated by a Polish general Maczek. (S4)

The students attempted to understand, contextualize and analyze the daily practices of the people from diverse cultures they met and observed (mainly other international students and local students). In the collected accounts of cross-cultural contacts where elements of criticism appeared, the respondents adopted the perspective of "general culture" - they resorted to cultural norms that are universal and applicable in a wide range of contexts, which is another indicator of intercultural development. For example, one female respondent expressed explicitly her dislike toward feminization of men, which, in her opinion, is a worldwide trend. Although she noticed it in a specific national context (Italy), her appeal to change the situation applied to all countries (i.e., a much wider context):

In Portugal men are obsessed with their look. A male friend of mine from Italy kept taking photos of himself in different settings to exhibit it on the Instagram, which I found irritating and unmanly. There is a need to start a crusade for maintaining masculinity. (S1)

\subsection{Developing personal coping strategies}

Narratives of quite a few students demonstrated that contact with peers from other cultures prompted them to develop a range of strategies helpful in crosscultural situations, which mirrors the results of other research (e.g., Czerwionka et al., 2015; Fang \& Baker, 2017; M itchell, 2012; Zaykovskaya et al., 2017). For example, one female informant said she realized that "dialog is the key to understand another individual and solve any problems in cross-cultural encounters" (S12). In addition, the study participants learned that preemptive judgment of people from different cultural backgrounds may lead to misunderstanding and thus to miscommunication. The students tried to limit assessment of their international peers ("I tried not to judge people, instead I tried to be mindful and observed them attentively" [S2]), and even if they evaluated them, they tried to "understand their perspective" (S3) or "to put themselves in their shoes and be empathetic toward them" (S12). One respondent admitted: "I became more mindful - I listen to people more attentively" (S4).

A great number of respondents stated that if they had encountered an ambiguous and incomprehensible situation, they had asked their interlocutors questions to elicit explanation. This was in line with recommendations by experts in intercultural communication, for example, the ones expressed by Ting-Toomey 
(1999) in her O-D-I-S model encouraging individuals to observe, describe, interpret and suspend judgment when confronted with foreigners or, more recently, by Berardo and Deardorff (2012) in their O-S-E-E model (observe, state, explore and evaluate). A few respondents revealed that they tried to compare their foreign peers' weird behaviors or views and find similarities with the ones typical of the Polish culture. The students also had a proactive approach to cross-cultural conflicts - they tried to foresee them in advance and either used an avoidance strategy or adapted accordingly to the situation in order to sidestep any problems.

\subsection{Changes in attitudes, views and behavior}

This study, like previous research (e.g., Czerwionka et al., 2015; Elola \& Oskoz, 2008; Fang \& Baker, 2017; M itchell, 2012; Zaykovskaya et al., 2017), found that all the students reported changes in both attitudes, views and behavior, which supports the developmental and context-based nature of ICC (Bennett, 1993; TingToomey, 1999). However, the extent of changes is not even, with some students reporting deeper transformation than others. Stereotypes and an essentialist approach to culture were still present in some narratives. It is also not clear from the obtained data to what extent the interview participants developed a sense of inclusive, intercultural identity that goes beyond the national one (Baker, 2015). Five of the informants expressed explicitly that although they were biased against foreigners prior to the sojourn, they managed to learn and change their views:

Spaniards are more conscientious and hard-working than I used to think. They are not as self-confident as I imagined - I have never met a shy Spaniard before. (S6)

The Dutch ride their bikes on a larger scale and use less toxic substances than I thought. (S4)

A few respondents admitted that the stay abroad helped them reject some stereotypes: "Contrary to what I thought before, the Spaniards do not come late" (S6), "the Finns are not cold and do not keep people at a distance; contrary to this, their mentality resembles Polish one" (S11).

Two female interviewees admitted they had been prejudiced against M uslims, whom they associated with terrorism and girls wearing headscarves. One of them was quite surprised that she had managed to establish her best relationship while abroad with Turkish students: "In close contact they turned out to be the same: their views on many things, such as, women's liberation, seem to be similar to mine. They are very tolerant toward homosexuals. Now I perceive their diverse clothing patterns as something positive" (S5). The other student realized, after spending some time among a few M uslim students from Pakistan, that the picture of Islam in the media in Poland is biased: "I didn't know that killing is forbidden 
according to Islam" (S1). The aforementioned narratives proved that critical reflection resulted in the respondents' identifying assumptions that underpinned their stereotypical views, evaluating their validity and reconstituting their understandings. The following narratives evidence more examples of the changes reported explicitly by the respondents:

I try to control assessing my interlocutors. I do it much less frequently now. (S1)

I have learned to approach people unprejudiced, without categorizing or labeling them. I have realized it is necessary to listen to them first and explore before making any assessment. (S4)

My truth used to be the most important. Now I can take somebody else's perspective. Every individual contributes something valuable. I started considering otherness as "added value." (S6)

I approach another person with a lower number of assumptions conceming who they are. (S7)

Staying among people from diverse cultures was an ordeal; yet in the aftermath, my comfort zone has extended tremendously. (S8)

Contact with foreigners helps an individual distance himself/herself from his/her own culture. I have broadened my horizons and became more inclusive; I have learned how to grapple with communication problems with people from diverse cultures. (S10)

I am more empathetic. I learned to listen to my interlocutors. I am more sensitive and open toward otherness, and find it much easier to cope with representatives of the multicultural world. Whenever I find something strange or incomprehensible I keep asking questions. I became more liberal. (S11)

I used to judge people in a very shallow and superficial way, often by forming snap judgments. Having spent one semester abroad, I have come to a conclusion that my assessment can be completely invalid and inaccurate, generalizations are often useless, and each individual has to be evaluated separately, depending on a specific context. Even if at the first glimpse something looks terrible, it does not necessarily mean bad intentions on the part of the interlocutor/s. I try to pay attention to nuances concerning what people are doing or saying. (S12)

In the respondents' views, the sojourn contributed to their personal development, especially with regard to their maturity and self-confidence. Their declared enhanced open-mindedness, avoidance of evaluative adjectives and more profound tolerance toward differences exerted a positive influence on their social and interaction skills:

It is not a problem for me anymore to start a conversation with a person from a different culture or to ask him/her a question. (S1) 
Never before did I witness a couple of the same sex kissing each other in public. I got used to this with time. (S2)

I find it much easier now to establish a contact with a Muslim. (S4)

It is much easier for me to find myself among people from other cultures. (S10)

\section{Conclusions and implications}

The interview-based study illustrated that the students attempted to be mindful in the rich, intercultural context and open-minded toward their international peers, and they eagerly engaged in meaningful contacts with them, regardless of the lack of formal preparation. The findings presented here are in line with other research on study abroad showing it as a largely positive experience for its participants, contributing to developing sensitivity to cultural differences, and a sense of intercultural awareness and competence (Beaven $\&$ Borghetti, 2015; Byram, Golubeva, Han, \& Wagner, 2017; Czerwionka et al., 2015; Elola \& Oskoz, 2008; Fang \& Baker, 2017; M itchell, 2012). Sojourn abroad raised students' surface knowledge about the host country and its citizens. The students took advantage of the ample opportunities to interact mainly with their international fellow students and if confronted with incomprehensible diversity they made commendable efforts to ask their interlocutors for explanations. However, since they did not have much access to local communities and did not fully immerse themselves in the host culture and language, they did not explore things on their own and did not have many opportunities to interpret the unique experiences they might have had otherwise. Consequently, they learned only to a limited extent that intercultural communication requires a lot of care and effort, and practiced an application of considered, reflective strategies moderately.

However, focusing on engagement with international peers, the interview sample tried not to bracket off cultural issues and adopted a reflexive stance toward cultural differences they faced. Such an approach activated the respondents' self-regulation and self-awareness, which resulted in their judgments and stereotypes of specific cultural groups or preconceived notions being challenged, processed and, in some cases, reviewed. Although a lot of ongoing national stereotyping has been reported, the students' narratives revealed that in the aftermath of the face-to face encounters with international peers some of their well-ingrained beliefs and views changed to a certain extent, making them more open-minded and inclusive toward diversity.

The study implies that the sojourn as an opportunity for meaningful interactions with both domestic and international students has considerable potential to enhance participants' global-mindedness, preparing them for variety, change and adaptation. Although success of a mobility experience depends on 
a number of factors, some of which may be difficult to predict, the findings of this research show pertinence of internationalizing study programs for students' intercultural growth. Thus, on a practical front, study abroad of at least one semester should become a mandatory element of university curricula. Consequently, students would be exposed to foreign culture(s) and provided with opportunities to reflect on the experience and act accordingly in future cross-cultural encounters, contributing, in the long run, to growth in their ICC.

The results also demonstrate that student mobility does not by itself guarantee intercultural development and the potential value of intercultural training - it is vitally relevant to ensure that students are aware of what they might encounter ahead of time, and what measures might help enhance their studying abroad experience. Such training could encourage students to immerse into the host country culture more eagerly and profoundly, and should contribute to sharpening their mindfulness and practicing reflection during the sojourn. Likewise, appropriate support, evaluation and opportunities for reflection upon return home are crucial to successful student mobility. This, of course, should be combined with teaching English as a global lingua franca at all levels of education.

Some limitations of the present study should be addressed. First, the research was carried out when the students had returned home - consequently not much was known about their ICC before the departure. A longitudinal study (i.e., data collected more periodically) in which the participants would be interviewed before departure, during and then after their stays abroad could be a source of valuable information by providing a greater opportunity for the analysis of students' intercultural development. Exploring the long-term results of student mobility would require examining the quality of students' intercultural contacts and maintenance of the social networks established abroad upon their returning home, as well as their lifestyle choices and a degree of civic engagement in the future. Critical reflection at all stages of the sojourn could deepen understanding of the experiences with cultural diversity and their impact on intercultural learning, allowing for validating possibly overly optimistic conclusions drawn in this study. Second, the applied methodology (i.e., semistructured interviews) definitely limited and shaped to a large extent the participants' narratives. It would be good to organize a focus group with a few of the interviewees to discuss the themes further. Minimum involvement on the part of the researcher and lack of prompts would ensure that the participants could express their unbiased opinions and would yield helpful insights into the researched issues. Third, the research was done on a small sample, who, in addition, self-elected to take part and probably were eager to report positively; thus the conclusions, as preliminary and tentative, cannot be generalized beyond the study group. To verify the results presented in this article, and to draw more reliable and valid conclusions, the study should be replicated on a larger, drawn sample of Polish EFL students at the tertiary 
level. Fourth, more helpful insight could be gained by complementing the present retrospective, qualitative study with the data received from other sources than interview accounts (i.e., students' diaries, journals, logs and e-portfolios). This would help validate the obtained data and, thereby, eventually increase the credibility of its findings and their interpretation.

In addition, the research documented only the perspective of the participants - the effectiveness of the sojourn was measured retrospectively, from the students' point of view, on the basis of their reports. Future studies should attempt to garner additional data sources and utilize a multi-perspective approach that would help solicit evidence from both students and people with whom they interacted. The evidence would be stronger if field observations of student performance in intercultural contexts were made by instructors, host family members or community members. Furthermore, the use of a control group could help bring considerable gains concerning to what extent the development of students' ICC can be attributed to student mobility itself and not to some other external factors that caused the changes. Finally, additional studies with a broader multinational perspective, focusing on other European students sojourning abroad are needed. Only triangulation of methods and sources will help us further pursue and investigate the matter thoroughly, and eventually allow for enhanced insight into the investigated topic, thus; giving reliable answers to the research questions. Short-term study abroad has enormous capacity to increase participants ICC, but their quality is contingent on a range of factors that are not yet fully understood. Thus, much more effort is still needed to explore the potential of international educational experience for fostering students' intercultural development and to analyze the correlation between both.

\section{Acknowledgements}

I would like to offer my sincere thanks to the participants involved in this study for their trust in my research, for without their understanding and cooperation it would not have been done. I would also like to express my gratitude to the anonymous reviewers for their useful comments, feedback and suggestions on the earlier draft of the manuscript. 
References

Allport, G. (1954). The nature of prejudice. Reading, MA: Addison-Wesley.

Altschuler, L., Sussman, N., \& Kachur, E. (2003). Assessing changes in intercultural sensitivity among physician trainees using the Intercultural Development Inventory. International Journal of Intercultural Relations, 27, 387-401.

Anderson, P., Lawton, L., Rexeisen, R., \& Hubbard, A. (2006). Short-term study abroad and intercultural sensitivity: A pilot study. International Journal of Intercultural Relations, 30, 457-469.

Ang, S., \& Van Dyne, L. (2008). Conceptualization of cultural intelligence: Definition, distinctiveness, and nomological network. In S. Ang \& L. Van Dyne (Eds.), Handbook of cultural intelligence: Theory, measurement, and applications (pp. 3-15). Armonk, NY: M .E. Sharpe.

Ang, S., Van Dyne, L., Koh, C., Ng, K. Y., Templer, K., Tay, C., \& Chandrasekar, N. A. (2007). Cultural intelligence: Its measurement and effects on cultural judgment and decision making, cultural adaptation and task performance. M anagement and Organization Review, 3(3), 335-371.

Baker, W. (2015). Culture and identity through English as a lingua franca: Rethinking concepts and goals in intercultural communication. Berlin: De Gruyter M outon.

Beaven, A., \& Borghetti, C. (2015). Editorial: Intercultural education for student mobility. Intercultural Education, 26, 1-5.

Bennett, J. M. (1993). Towards ethnorelativism: A developmental model of intercultural sensitivity. In R. M. Paige (Ed.), Education for the intercultural experience (pp. 21-71). Yarmouth, M E: Intercultural Press.

Bennett, J. M ., Bennett, M. J., \& Allen, W. (1999). Developing intercultural competence in the language classroom. In R. M. Paige, D. Lange, \& Y. A. Yershova (Eds.), Culture as the core: Integrating culture into the language classroom (pp. 13-46). Minneapolis, M N: University of M innesota Press.

Berardo, K., \& Deardorff, D. (2012). Building cultural competence: Innovative activities and models. Sterling, VA: Stylus.

Byram, M. (2000). Routledge encyclopedia of language teaching and learning. London: Routledge.

Byram, M., Golubeva, I., Han, H., \& Wagner, M. (2017). From principles to practice in education for intercultural citizenship. Bristol: $M$ ultilingual $M$ atters.

Corbin, J., \& Strauss, A. (2007). Basics of qualitative research: Grounded theory procedures and techniques (3rd ed). Thousand Oaks, CA: Sage.

Cushner, K., \& Brislin, R. (1996). Intercultural interactions: A practical guide. Thousand Oaks, CA: Sage. 
Cushner, K., \& Karim, A. (2003). Study abroad at the university level. In D. Landis, M. Bennett, \&J. M. Bennett (Eds.), Handbook of intercultural training (pp. 289-308). Thousand Oak, CA: Sage.

Czerwionka, L., Artamonova, T., \& Barbosa, M. (2015). Intercultural knowledge development: Evidence from student interviews during short-term study abroad. International Journal of Intercultural Relations, 49, 80-99.

Czura, A. (2017). Student teachers' recollections of a short-term study abroad experience: Critical incident analysis. Konin Language Studies, 5(1), 135-156. Deardorff, D. (2006). Identification and assessment of intercultural competence as a student outcome of internationalization. Journal of Studies in International Education, 10(3), 241-266.

Desforges, D., Lord, C., Pugh, A., Sia, L., Scarberry, C., \& Ratcliff, D. (1997). Role of representativeness in the generalization part of the contact hypothesis. Basic and Applied Social Psychology, 19, 183-204.

Deutsch, K. (1953). Nationalism and social communication. Cambridge, Mass.: MIT. Earley, P. Ch., \& Ang, S. (2003). Cultural intelligence: Individual interactions across cultures. Palo Alto, CA: Stanford University Press.

Engle, L., \& Engle, J. (2004). Assessing language acquisition and intercultural sensitivity development in relation to study abroad program design. Frontiers: The Interdiscipilnary J ournal of Study Abroad, X(Fall), 151-163.

Elola, I., \& Oskoz, A. (2008). Blogging: Fostering intercultural competence development in foreign language and study abroad contexts. Foreign Language Annals, 41(3), 454-477.

Fang, F., \& Baker, W. (2017). A more inclusive mind towards the world: English language teaching and study abroad in China from intercultural citizenship and English as a lingua franca perspective. Language Teaching Research, 22, 1-17. Fligstein, N. (2008). Euroclash: The EU, European identity, and the future of Europe. Oxford: Oxford University Press.

Gaertner, S., Dovidio, J., Anastasio, P., Bachman, B., \& Rust, M . (1993). The common ingroup identity model: Recategorization and the reduction of ingroup bias. European Review of Social Psychology, 4(1), 1-26.

Halse, C. (1996). Cultures of curriculum change: Teachers' stories of implementing studies of Asia. Nepean: University of Western Sydney.

Halualani, R. T. (2008). How do multicultural university students define and make sense of intercultural contact? A qualitative study. International Journal of Intercultural Relations, 32(1), 1-16.

Hamberger, J., \& Hewstone, M . (1997). Inter-ethnic contact as a predictor of blatant and subtle prejudice: Test of a model in four West European nations. British Journal of Social Psychology, 36, 173-190. 
Hean, S., \& Dickinson, C. (2005). The contact hypothesis: An exploration of its further potential in interprofessional education. Journal of Interprofessional Care, 19(5), 480-491.

Hewstone, M . (1994). Revision and change of stereotypic beliefs: In search of the elusive subtyping model. In W. Stroebe $\&$ M. Hewstone (Eds.), European review of social psychology (Vol. 5; pp. 69-109). Chichester, UK: Wiley.

Hill, B., \& Thomas, N. (2002). Preparing Australian teachers to teach Asian studies: The importance of in-country experience. Asia-Pacific Journal of Teacher Education, 30, 291-298.

Jackson, J. (2015). Becoming interculturally competent: Theory to practice in international education. International J ournal of Intercultural Relations, 48, 91-107.

Kelly, G. (1963). A theory of personality. New York: Norton.

Kormos, J., \& Csizér, K. (2007). An interview study of intercultural contact and its role in language learning in a foreign language environment. System, 35(2), 241-258.

Liddicoat, A., \& Scarino, A. (2013). Intercultural language teaching and learning. Hoboken, NJ: Wiley-Blackwell.

Lussier, D. (2007). Theoretical bases of a conceptual framework with reference to intercultural communicative competence. Journal of Applied Linguistics, 4(3), 309-332.

Mak, A. S., Brown, P. M., \& Wadey, D. (2014). Contact and attitudes toward international students in Australia: Intergroup anxiety and intercultural communication emotions as mediators. Journal of Cross-Cultural Psychology, 45(3), 491-504.

M cAllister, L., Whiteford, G., Hill, B., Thomas, N., \& Fitzgerald, M . (2006). Reflection in intercultural experience through a critical incident approach. Reflective Practice, 7(3), 367-381.

McCabe, L (2001). Globalization and internationalization: The impact on education abroad programs. Journal of Studies in International Education, 5(2), 138-145.

Mitchell, K. (2012). Student mobility and European identity: Erasmus Study as a civic experience? Journal of Contemporary European Research, 8(4), 490-518.

Murphy-Lejeune, E. (2002). Student mobility and narrative in Europe: The new strangers. London: Routledge.

Otero, M. S., \& M cCoshan, A. (2006). Survey of the socio-economic background of Erasmus students: Final report. Birmingham, UK: ECOTEC Research and Consulting.

Paige, R. M. (1993). On the nature of intercultural experiences. In R. M. Paige (Ed.), Education for the intercultural experience (pp. 1-19). Yarmouth, ME: International Press. 
Paige, R. M ., Cohen, A. D., \& Shively, R. L. (2004). Assessing the impact of a strategies-based curriculum on language and culture learning abroad. Frontiers: The Interdiscipilnary Journal of Study Abroad, X(Fall), 253-276.

Pettigrew, T., \& Tropp, L. R. (2005). Allport's intergroup contact hypothesis: Its history and influence. In J. F. Dovidio, P. Glick, \& L. Rudman (Eds.), On the nature of prejudice fifty years after Allport (pp. 262-277). Malden, M A: Blackwell.

Pettigrew, T., Tropp, L., Wagner, U., \& Christ, O. (2011). Recent advances in intergroup contact theory. International Journal of Intercultural Relations, $35,271-280$.

Rice, P., \& Ezzy, D. (1999). Qualitative research methods: A health focus. Melbourne: Oxford University Press.

Seidlhofer, B. (2011). Understanding English as a lingua franca. Oxford: Oxford University Press.

Silverman, D. (2013). Doing qualitative research. Los Angeles, CA: Sage.

Simpson, J. (2008). "What do you think of us?": The pedagogical practices of cross-cultural communication, misrecognition, and hope. Journal of International and Intercultural Communication, 1, 181-201.

Stangor, C., Jonas, K., Stroebe, W., \& Hewstone, M. (1996). Influence of student exchange on national stereotypes, attitudes and perceived group variability. European Journal of Social Psychology, 26, 663-675.

Tang, S., \& Choi, P. (2004). The development of personal, intercultural and professional competence in international field experience in initial teacher education. Asia Pacific Education Review, 5(1), 50-63.

Ting-Toomey, S. (1999). Communication across cultures. New York, NY: Guilford Press. Townley, G., Kloos, B., Green, E., \& Franco, M. (2011). Reconcilable differences? Human diversity, cultural relativity, and sense of community. American Journal of Community Psychology, 47, 69-85.

Vande Berg, M. (2007). Intervening in the learning of US students abroad. Journal of Studies in International Education, 11(3-4) 392-399.

Van Dick, R., Wagner, U., Pettigrew, T., Christ, 0., \& Wolf, C. (2004). Role of perceived importance in intergroup contact. Journal of Personality and Social Psychology, 87(2), 211-227.

Wilson, A. (1983). A case study of two teachers with cross-cultural experience: They know more. Educational Research Quarterly, 8(1), 78-85.

Zaykovskaya, I., Rawal, H., \& De Costa, P. (2017). Learner beliefs for successful study abroad experience: A case study. System, 71, 113-121. 


\section{APPENDIX}

\section{Interview questions}

Part I

1. Where did you study? How long?

2. Why did you want to participate in Erasmus+program? Do you think you achieved your goals associated with studying abroad?

3. Did you travel abroad a lot individually before Erasmus+ program? How often? Where? Did you keep in touch on a regular basis with a person/people from different cultures before studying abroad?

4. Did you prepare for study abroad? How? Did you try to learn about the country, its inhabitants, culture, etc.? Did you take part in intercultural training?

5. How much time did you spend with locals/foreigners while studying abroad? Did you have a local/foreign roommate? What was his/her nationality? Did you manage to become a friend with anybody or establish any meaningful contacts?

Part II (All the following questions refer to your Erasmus experience)

6. What did you learn about the country where you studied and

a) its culture

b) its daily life (e.g., the people, food and drink, meals, pace of life, nightlife habits, smoking, fashion - specify)

Did the study abroad confirm the knowledge you had about the country, its inhabitants and the culture or help reject stereotypes and break down prejudices?

7. Did you notice any differences between life in Poland and in the country you stayed (e.g., social nuances of the host society, the way people dress or behave, what is acceptable/unacceptable). How did you feel about it?

8. Were you given any assignments which required pair- or group-work with (a) local or other foreign student(s)? Did you notice any differences in the way they work or communicate? Did you ever have problems understanding your interlocutor not because of your linguistic incompetence or language barrier, but because of culturally determined reasons? Explain the nature of the problem/s and state how you tried to solve it/them?

9. Did you ever witness something strange by your cultural standards, and thus incomprehensible for you to understand in the behavior of local people/other Erasmus students? If you did, did you try to analyze what lay behind it? Did you ever try to learn why they behave the way they do or react in certain ways?

10. Did you ever encounter people whose norms, opinions, beliefs, conventions or values were completely different from yours (or which prevail in your culture)? Were you ever surprised/shocked because of it? Did this difference/these differences ever lead to a conflict? If yes, did you know how to deal with such conflicts? How did you try to solve them?

11. Did you ever experience discomfort because of your interlocutor's "strange" behavior, opinions, beliefs, conventions or values? 
12. How did you behave/react when you encountered such strange behavior (the one unacceptable by your cultural norms)? Was contact with foreign/strange values, beliefs and norms an impulse to self-reflect and self-analyze, namely think about your own values, beliefs and norms by which you are guided and how they affect your perception of others? Did you talk about this to anybody? While encountering something strange or incomprehensible, did you try to explore the interlocutor's perspective to understand what was going on or did you look at them through your own cultural lenses?

13. While you were talking to locals/foreigners did you evaluate their look, values, beliefs and behavior as normal/abnormal, strange, weird, acceptable/ not acceptable?

14. Did contact with locals/foreigners change anything in how you feel and approach otherness, namely your openness, tolerance, respect, appreciation, e.g., people dressed unconventionally, same sex couples, people of other religious denominations than your own, people with completely different political orientation, etc.?

15. What did you learn about yourself? (did you identify new parts of yourself, did you find any discrepancies between what you claim to value versus what you do in practice). Do you perceive yourself in a new way after studying abroad for one semester? Did you change? If you changed, how did you change and why? What do you think mostly contributed to this? 